\title{
Predestination and the Protestant Ethic
}

\author{
Larbi Alaoui* Alvaro Sandroni ${ }^{\dagger}$
}

January 9, 2013

\begin{abstract}
This paper shows an equivalence result between the utility functions of secular agents who abide by a moral obligation to accumulate wealth and those of religious agents who believe that salvation is immutable and preordained by God. This result formalizes Weber's renowned thesis on the connection between the worldly asceticism of Protestants and the religious premises of Calvinism. Furthermore, ongoing economies are often modeled with preference relations such as "Keeping up with the Joneses" which are not associated with religion. Our results relate these secular economies of today and economies of the past shaped by religious ideas.
\end{abstract}

*Universitat Pompeu Fabra and Barcelona GSE. E-mail: larbi.alaoui@upf.edu

${ }^{\dagger}$ Kellogg School of Business. E-mail: sandroni@kellogg.northwestern.edu. Alaoui gratefully acknowledges financial support from the Spanish Ministry of Science and Innovation under project ECO201125295, and Sandroni gratefully acknowledges financial support from the National Science Foundation. We thank Luigi Pascali, Helena Perrone, Davide Cantoni, Stephen Hansen, Benito Arruñada and participants at the SAET conference and the Latin American meeting of the Econometric Society for helpful comments and suggestions. We especially thank Weifeng Zhong for his excellent research assistance. All errors are ours. 


\section{Introduction}

This paper relates Weber's thesis on the religious origins of the Protestant ethic, the Kreps-Porteus (1978) model of preferences for early resolution of uncertainty and "Keeping up with the Joneses" preferences that are used to accommodate asset prices and aggregate variables of ongoing economies. In The Protestant Ethic and the Spirit of Capitalism (2002, first published as a two part article 1904-05), Max Weber argues that Protestantism fosters an environment conducive to economic development because it instills the idea that earning and accumulating wealth is a moral obligation. According to this viewpoint, wealth ought to be obtained as an end in itself, at most for the satisfaction of having succeeded in business, and not for it's commonplace use in procuring consumption, leisure, power and social recognition. Weber notes that while contemporaneous Protestants often abided by the Protestant ethic, they were also typically indifferent, if not hostile, towards the Church. They feel "the attempts of religion to influence economic life, in so far as they can still be felt at all, to be as much as an unjustified interference as its regulation by the State." ${ }^{1}$ Yet, Weber argues that the Protestant ethic originated in religious' beliefs and, in particular, in the Calvinist doctrine of predestination: the idea that some humans are in a state of grace and, hence, destined to salvation while others are damned, the choice being immutable and preordained by God.

Weber's thesis remains one the most celebrated, and polemic, works of social science because it puts forward an appreciation of metaphysical ideas as effective forces in the formation of economies. This paper uses decision-theoretic tools to examine the connection between the secular Protestant ethic and the religious premises of Calvinism. Going beyond Weber's thesis, we examine links between Calvinism and preferences such as Keeping up with the Joneses that are used in the analysis of modern economies.

Protestant ethics is formally modeled by an expected utility for wealth, independent of consumption or any other benefit, that takes the form

$$
E v\left(w^{i}-W\right)
$$

where $w^{i}$ is agent $i$ 's earned wealth and $W$ is the average wealth, employed as a benchmark to measure performance. The use of aggregate wealth as a reference implies that utility diminishes when others' wealth and consumption increases. In particular, the utility function in (1) is formally equivalent to standard Keeping up with the Joneses preferences, but with a different interpretation.

\footnotetext{
${ }^{1}$ Conversely, "The old Protestantism of Luther, Calvin, Knox, Voet, had precious little to do with what to-day is called progress."
} 
The proper model of Calvinism has been extensively debated. The main difficulty is that Calvinists often lived a frugal life of hard work and, according to their faith, an ascetic lifestyle does not deliver any reward of salvation. The question then is what motivates Calvinists to austerity. One view is that Calvinists' anxieties over their salvation lead them to confuse the causes and consequences of their actions, thereby succumbing into a form of "magical thinking" (see Elster (2007)). In a similar way, Quattrone and Tversky (1984) argue that Calvinists may "confuse diagnostic and casual contingencies" (see also Bodner and Prelec (2003) and Benabou and Tirole (2004, 2006, 2011) on self-deception and diagnostic utility).

Weber upholds that the intense psychological impact of Calvinism was in part due to it's "iron consistency" and lack of vacillation between competing dogmas. We build upon Weber's perspective and model Calvinists as fully rational in a traditional economic sense. We assume that Calvinists believe that grace is conducive to success in business; that wealth is a sign, never a means, of grace; and that the signs of grace are more informative if more wealth is earned, saved and reinvested as capital in risky enterprises. Finally, Calvinists are motivated by the need to obtain informative signs of grace in their lifetime. The Kreps and Porteus (1978) axiomatic model of recursive expected utility is crucial to formally model these ideas because it can accommodate a strict preference for early resolution of uncertainty (e.g., a preference for an informative sign of grace during one's lifetime rather than in the afterlife). This preference for early resolution of uncertainty is above and beyond any instrumental value of early acquisition of information, as it must be in the case of an immutable state such as grace. Accordingly, we model Calvinists with Kreps-Porteus utility functions of the form

$$
E u_{C}\left(p\left(g^{i}=g \mid \gamma^{i}, s^{i}-S\right)\right)
$$

where $p\left(g^{i}=g \mid \gamma^{i}, s^{i}-S\right)$ is agent $i$ 's Bayesian posterior belief of grace, contingent on his savings (compared to aggregate levels) and the idiosyncratic shock on his investments. The Kreps-Porteus model has an axiomatic foundation that is similar to the axiomatic foundation of expected utility theory and is widely understood as a natural extension of expected utility. In this sense, our standpoint on the beliefs and behavior of Calvinists is consistent with the models and axioms of standard economic theory.

In spite of differences in interpretation and functional forms between (1) and (2), our main result shows, under suitable conditions, an exact equivalence between the class of utility functions of Protestant ethics and Calvinists. This result is central in our analysis because it formalizes Weber's thesis of a deep connection between secular agents who abide by the Protestant ethic and religious agents who believe in the Calvinist doctrine 
of predestination. Thus, the seemingly naive, but highly tractable, model of Protestant ethics given by (1) has foundations based on Weber's thesis. Moreover, qualitative insights obtained by utility functions of secular agents can be transmitted to economies where agents are religious. For example, the Protestant ethic utility functions (1) have the Keeping up with the Joneses' property of a negative externality when aggregate wealth and consumption increases. So, even if Calvinists do not care about their social status and are primarily concerned with their individual salvation, their competitive struggle for informative signs of grace makes them overwork and oversave from a welfare perspective.

This paper is structured as follows: Section 1.1 presents a brief literature review, and Section 2 introduces the model and the different types of agents. Section 3 presents the main equivalence result. Section 4 concludes.

\subsection{Related literature}

A large literature, that we do not survey here, studies Weber's thesis from an empirical and historical viewpoint (see, among many contributions, Guiso, Sapienza and Zingales (2003, 2006) for a discussion on culture and economic outcomes and Blum and Dudley (2001), Ekelund, Hebert and Tollison (2002), Cavalcanti, Parente and Zhao (2007), Becker and Woessman (2009), Cantoni (2010), Arruñada (2010) for discussions, literature reviews and empirical analyses of Weber's thesis. See also Glaeser and Glendon (1998) for a model and empirical study of predestination compared to free will). Recently, theoretical frameworks have also examined Calvinism. Bodner and Prelec (2003) note that their model of self-diagnosis might be applied to Calvinists if they had a preference for self-signaling. Benabou and Tirole $(2004,2006,2011)$ discuss an application of their framework to Calvinism, under the interpretation that increases in effort is indicative of grace. Dal Bó and Tervio (2012) consider a model of internal reputation in which moral choices (e.g., resisting temptation) directly affect self-esteem. Levy and Razin (2012) examine self versus social signaling for Calvinists' players in a repeated game. These models can be seen as dual selves models in which one self of the agent learns about himself from the behavior of his other self (see Brunnermeier and Parker (2005) and Koszegi (2006) for planner-doer self models).

Our main objective is radically different from the existing literature. We formalize Weber's thesis on the connection between the religious doctrine of predestination and the secular Protestant ethic. This motivation is not shared by any theoretical paper that we know of. Moreover, unlike the existing literature, in our model, Calvinists do not learn about their state of grace directly by their actions. Instead, their actions may only change 
the informativeness of their signs of grace (that arise from the results of their business projects).

A growing theoretical literature examines different religions. Azzi and Ehrenberg (1975) analyze household decisions to attend church. Iannaccone (1992) models religion as a club good, Berman (2000) studies choices of Ultra-Orthodox Jews and Bisin and Verdier (2001) model cultural transmission mechanisms. Levy and Razin (2012b, 2012c) analyze social signaling in religious organizations, and explore the connection between religious beliefs and social cooperation. Tabellini (2008) models preferences in which norms of conduct can be transmitted to future generations, and mentions religion as a possible interpretation.

\section{Model}

There are two periods and a continuum of agents normalized to 1. Each individual lives in both periods. Agent $i$ is endowed with $\bar{l}$ units of time that is used, in the first period, for labor $\left(l^{i}\right)$ and leisure $\left(\bar{l}-l^{i}\right)$. Agents live in autarchy and they each have the same strictly increasing and concave production function $f$ with labor as the input. At the beginning of period 1 , agent $i$ produces $f\left(l^{i}\right)$. At the end of period 1 , he consumes $c_{1}^{i}$ and saves $s^{i}=f\left(l^{i}\right)-c_{1}^{i}$. In period 2 he receives wealth $w^{i}=\left(s^{i}+\gamma^{i} \theta\right)(1+r)$, where $r>0$ is a fixed return on investment, $\theta$ is an aggregate shock and $\gamma^{i}$ is agent $i$ 's individual shock. Both $\theta$ and $\gamma^{i}$ belong to finite sets: $\theta \in\{\underline{\theta}, \ldots, \bar{\theta}\}, \underline{\theta}>0$, and $\gamma^{i} \in\{\underline{\gamma}, . ., \bar{\gamma}\}, \underline{\gamma}>0$. The distribution of the individual shock $\gamma^{i}=\gamma$ is identical for all agents and independent across agents. The mean of $\gamma$ is 1 . The probabilities of $\gamma$ and $\theta$ are denoted $p(\gamma)$ and $p(\theta)$. Finally, at the end of period 2, agent $i$ consumes $c_{2}^{i}=w^{i}$.

The assumption that consumption in the last period equals earned wealth (i.e., $c_{2}^{i}=$ $w^{i}$ ) highlights that all results hold without externalities on consumption and production of goods. However, this assumption can be disposed of. Our main result holds even if earned wealth were taxed and arbitrarily redistributed for consumption, i.e., $c_{2}^{i} \neq w^{i}$.

$L$ denotes the average labor, $S$ is the average saving, $C_{1}$ and $C_{2}$ are the average period 1 and period 2 consumption, respectively, and $W$ is the average wealth. ${ }^{2}$ These aggregate variables are observed by all agents (in each period). ${ }^{3}$ Changes in aggregate variables have no impact on any individual's production function. We also assume that the lowest individual shock, $\underline{\gamma}$, is sufficiently low.

\footnotetext{
${ }^{2}$ Formally, $L=\int_{i \in[0,1]} l^{i} d i$, and an analogous equation holds for $S, C_{1}, C_{2}$ and $W$.

${ }^{3}$ We use the terms 'average' and 'aggregate' interchangeably because the continuum of agents has been normalized to 1 .
} 
Assumption R1 The lowest individual shock $\underline{\gamma}$ satisfies $\underline{\gamma}<\gamma-(f(\bar{l})-f(\underline{l})) / \bar{\theta}$ for all $\gamma>\underline{\gamma}$, where $\gamma \in\{\underline{\gamma}, \ldots, \bar{\gamma}\}$.

The probability of the lowest shock $\underline{\gamma}$ can be arbitrarily small. Hence, this is a common assumption of rare disasters, adapted to our purposes (see Barro (2009)). This technical assumption simplifies the analysis and several parts of our main result do not require it. Assumption R1 can also be replaced with the assumption that the highest shock is sufficiently high. ${ }^{4}$ We discuss the role of this assumption in detail in the Appendix.

\subsection{General preferences}

All decision-makers have (strictly increasing and concave) utility function $u$ in consumption for each period, a (strictly increasing and convex) disutility function $d$ in labor and an additional term $V$. So, a generic agent $i$ maximizes:

$$
U^{i}=\left[u\left(c_{1}^{i}\right)+\beta E u\left(c_{2}^{i}\right)-d\left(l^{i}\right)\right]+V^{i}\left(c_{1}^{i}, c_{2}^{i}, w^{i} ; C_{1}, C_{2}, W\right)
$$

s.t. budget constraint $[\mathrm{BC}]$ :

$$
\begin{aligned}
& c_{1}^{i}=f\left(l^{i}\right)-s^{i} ; w^{i}=\left(s^{i}+\gamma^{i} \theta\right)(1+r) ; \\
& c_{2}^{i}=w^{i}, 0 \leq l^{i} \leq \bar{l} ; 0 \leq s^{i} \leq f\left(l^{i}\right) .
\end{aligned}
$$

All functions in our analysis are smooth and allow for an interior solution. The expectation operator $E$ is taken over the aggregate stochastic shock $\theta$ and the individual shock $\gamma^{i}$. For example, $E u\left(c_{2}^{i}\right)=\sum_{\gamma^{i}, \theta} p\left(\gamma^{i}\right) q(\theta) u\left(c_{2}^{i} \mid \gamma^{i}, \theta\right) .{ }^{5}$ All agents face the same budget constraint, henceforth $B C$, and $\beta \in(0,1]$ is the discount factor.

The term $\left[u\left(c_{1}^{i}\right)+\beta E u\left(c_{2}^{i}\right)-d\left(l^{i}\right)\right]$ is common to all decision-makers. We refer to standard agents as those for whom $V^{i}\left(c_{1}^{i}, c_{2}^{i}, w^{i} ; C_{1}, C_{2}, W\right)=0$.

\subsection{Protestant Ethics and Keeping up with the Joneses}

Protestant ethics agents are assumed to be secular and indifferent towards religious concepts. Their main distinguishing feature is their determination to accumulate wealth for its own sake, rather than for the rewards (e.g., consumption, power, prestige) that wealth may bring about. Protestants believe that it is a moral obligation to accumulate wealth

\footnotetext{
${ }^{4}$ Specifically, the alternative assumption is that $\bar{\gamma}>\gamma+(f(\bar{l})-f(\underline{l})) / \bar{\theta}$ for all $\gamma<\bar{\gamma}$, where $\gamma \in$ $\{\underline{\gamma}, \ldots, \bar{\gamma}\}$. Both assumptions can also be interpreted as requiring high enough aggregate shock $\bar{\theta}$.

${ }^{5}$ It is straightforward to show that the agent can deduce $\gamma^{i}$ and $\theta$, ex-post, from $s^{i}, S, w^{i}$ and $W$.
} 
and average wealth is a benchmark used to measure performance. Let the Protestant ethics utility class $\left(\mathfrak{U}_{P E}\right)$ be all utility functions $U^{i}$ such that

$$
V^{i}\left(c_{1}^{i}, c_{2}^{i}, w^{i} ; C_{1}, C_{2}, W\right)=E v\left(w^{i}-W\right),
$$

where $v^{\prime}>0$. So, a Protestant ethics agent utility function is in $\mathfrak{U}_{P E}$. This holds whether or not each individual consumes his earned wealth in the last period (i.e., even if $c_{2}^{i} \neq w^{i}$ ). The renowned work ethic of Protestants follows from their preferences.

Remark 1. Given any values of the aggregate variables, any Protestant ethics agent works more, saves more and has higher expected wealth than a standard agent.

So, an economy consisting of Protestant agents produces more (in and out of equilibrium) than an economy comprising of standard agents.

Keeping up with the Joneses $(K U J)$ preferences are such that utility diminishes when others' consumption increases. ${ }^{6}$ These preferences play an important role in the analysis of modern economic behavior and are commonly used in macroeconomics and finance to fit empirical regularities. Abel (1990) argues that Catching up with the Joneses preferences can explain empirical puzzles in asset price trends; Gali (1994) analyzes the connection between consumption externalities and asset prices; Campbell and Cochrane (1995) also use a negative externality from aggregate consumption to explain trends in aggregate stock market behavior and several other aggregate variable; Dupor and Liu (2003) consider the effects of jealousy on overconsumption; and Ljungqvist and Uhlig (2000) analyze tax policies under "Keeping up" and "Catching up" with the Joneses. ${ }^{7}$

The typical interpretation of $K U J$ preferences are based on ideas such as jealousy and envy and not on morality. However, as long as aggregate wealth and consumption are positively related, the utility of Protestant ethics agents decreases when aggregate consumption increases. So, the utility functions of Protestants are, formally, $K U J$ preferences. In the special case that each individual consumes his earned wealth in the last period (i.e., $c_{2}^{i}=w^{i}$ ) then the utility function of Protestants are the usual Keeping up the Joneses utility functions such that $V^{i}=E v\left(c_{2}^{i}-C_{2}\right)$.

\footnotetext{
${ }^{6} \mathrm{~A}$ distinction is sometimes made between utility that is diminishing in aggregate consumption and an increase in marginal utility of consumption as aggregate consumption increases (see, for instance, Dupor and Lui (2003)). While we focus on the former, conditions for the latter are also provided in the Appendix.

${ }^{7}$ See also Rege (2008) for a model of social status and Maccheroni, Marinacci and Rustichini (2012) for a discussion on envy.
} 


\subsection{Calvinists}

While Protestant ethics agents outlook is directed towards worldly affairs, Calvinists are concerned with the afterlife. The central tenet of Calvinism is the doctrine of predestination: an individual $i$ is either in a state of grace $\left(g^{i}=g\right)$, and, hence, saved from damnation, or he is not $\left(g^{i}=n\right)$. The choice has been predetermined by God and is not influenced by any action that anyone (including agent $i$ ) might take. A Calvinist does not know whether he is in a state of grace. However, earned wealth can be seen as a signal, not a means, of grace.

\subsubsection{Wealth as a signal of grace}

Rational inferences about grace follow from two Calvinist premises: Grace is a tool of divine will and, hence, is conducive to success. Acquiring, saving and reinvesting wealth leads to better signals of grace. We formalize these two claims as assumptions WI and WII, respectively, but a simple example may deliver the gist of the idea. Consider the extreme case in which an individual shock can be either high or low and that a Calvinist believes: that his prior probability of grace is 0.5 ; that if his savings are low then both shocks have equal odds regardless of his state of grace; and that if his savings are high then he gets a high shock when he is in grace and a low shock when he is not. It follows from these premises that if his savings are low then he learns nothing about his state of grace (i.e., his posterior belief over his state of grace is still 0.5) and if his savings are high then he learns his state of grace perfectly (i.e., if his shock is high he is in grace and if his shock is low he is not). Thus, Calvinists do not receive a signal of grace from their choice of savings. Savings only increases the informativeness of the signal. ${ }^{8}$

Calvinists make rational inferences given their theological premises and these premises cannot be empirically tested. A claim of correlation between grace and success cannot be tested because grace is not observable even by proxy, unless it is assumed that some other observable variable is also correlated with grace. Finally, all agents (Calvinist or not) place the same odds over all observable variables. Thus, Calvinists's beliefs are consistent with Bayes' rule and are rational in the standard economics sense.

The general signal structure is formalized as follows: Let $p_{g}$ be the prior probability of grace. Let $p\left(\gamma^{i} \mid g^{i}, s^{i}-S\right)$ be the probability of receiving shock $\gamma^{i}$, given a state of grace $g^{i}$ and relative savings $s^{i}-S$. Similarly, $p\left(g^{i}=g \mid \gamma^{i}, s^{i}-S\right)$ denotes the updated probability of grace given relative savings $s^{i}-S$ and realized shock $\gamma^{i}$. The assumption that Calvinists associate grace with a higher likelihood of success is captured by the following

\footnotetext{
${ }^{8}$ Calvinists believe that hard work leads to better signals of grace. We focus on savings for simplicity.
} 
version of the monotone likelihood ratio property:

Assumption WI (MLRP): Given any relative savings $s^{i}-S \in[-f(\bar{l}), f(\bar{l})]$, and individual shocks $\gamma^{i}, \gamma^{i i} \in[\underline{\gamma}, \bar{\gamma}], \gamma^{i}>\gamma^{i} \Leftrightarrow \frac{p\left(\gamma^{i} \mid g^{i}=g, s^{i}-S\right)}{p\left(\gamma^{i} \mid g^{i}=n, s^{i}-S\right)}>\frac{p\left(\gamma^{\prime i} \mid g^{i}=g, s^{i}-S\right)}{p\left(\gamma^{\prime i} \mid g^{i}=n, s^{i}-S\right)}$.

So, Calvinists believe that good individual shocks are more likely when in grace.

Assumption WII (Informativeness): For any relative savings $s^{i}-S>s^{i}-S^{\prime}$, there is a nonnegative function $h$ on $[\underline{\gamma}, \bar{\gamma}] \times[\underline{\gamma}, \bar{\gamma}]$ such that: (i) $\sum_{\gamma^{\prime} \in[\underline{\gamma}, \bar{\gamma}]} h\left(\gamma^{\prime}, \gamma\right)=1$ for all $\gamma, \gamma^{\prime} \in[\underline{\gamma}, \bar{\gamma}]$ and (ii) $p\left(\gamma^{i} \mid g^{i}, s^{i}-S^{\prime}\right)=\sum_{\gamma \in[\underline{\gamma}, \bar{\gamma}]} h\left(\gamma^{\prime i}, \gamma\right) p\left(\gamma \mid g^{i}, s^{i}-S\right)$ for $g^{i} \in\{n, g\}$ That is, the informativeness of the signals of grace (in the usual Blackwell sense) is higher for larger relative savings. ${ }^{9}$ This does not imply that savings alter the distribution of individual shocks, which is fixed and unaffected by savings.

Signals are taken over relative savings in assumptions WI and WII. It is difficult to gauge objectively what constitutes high savings. In the absence of an absolute benchmark, it is common to use a relative one (as in social comparison theory, see Festinger (1954)). Moreover, even if agents were to use absolute standards, higher aggregate savings would still negatively impact the informativeness of individual signals whenever aggregate variables were not perfectly observable. The use of relative standards simplifies the analysis because it does not require imperfect observations of aggregate variables.

\subsubsection{Predestination and preferences for early resolution of uncertainty}

We now return to the main tenet of Calvinism: the doctrine of predestination. If it is impossible to influence God's choices then it is natural to ask about the incentives to follow religious teachings or to acquire costly information about grace. Weber points out that salvation was a critical concern of believers and so it became psychologically necessary to obtain means of recognizing grace. Even if grace is immutable, Calvinists still prefer to obtain signs of grace during their lifetime rather than to have it revealed only in the afterlife. The Kreps and Porteus (1978) model is critical to capture this aspect of Calvinism because it allows for preferences for early resolution of uncertainty. Accordingly, we use the Kreps and Porteus (1978) model and assume that a Calvinist agent $i$ has an utility function $V^{i}$ of the form

\footnotetext{
${ }^{9}$ For a more thorough discussion of Blackwell's theorem, see Marschak and Radner (1972), Kim (1995) and Grant, Kajii and Polak (2000).
} 


$$
V^{i}=E u_{C}\left(p\left(g^{i}=g \mid \gamma^{i}, s^{i}-S\right)\right),
$$

where $u_{C}$ is strictly increasing and convex and the expectation operator $E$ is taken, as usual, over aggregate and individuals shocks. ${ }^{10}$

The assumption that $u_{C}$ is increasing follows from the notion that Calvinists prefer being in grace than not. The convexity of the function $u_{C}$ implies that a Calvinist prefers to learn about his state of grace sooner rather than later. To see this point, consider the case in which the agent has the choice between discovering his state of grace in period 2 or remaining with his prior over grace $\left(p_{g}\right)$ in his lifetime. If he knows he will learn his state of grace in period 2 , his expected utility is $p_{g} u_{C}(1)+\left(1-p_{g}\right) u_{C}(0)$. This follows because with probability $p_{g}$ he learns in period 2 that he is in grace and with probability $1-p_{g}$ he learns that he is not. If, instead, he remains with his prior then his expected utility is $u_{C}\left(p_{g}\right)$. Thus, if $u_{C}$ is convex then the agent prefers to learn about his state of grace earlier. Extending this reasoning, it follows that $u_{C}$ is convex if and only if the agent prefers early resolution of uncertainty, as is shown by Kreps-Porteus (1978).

Let $\mathfrak{U}_{C}$, the utility class of Calvinists, be such that (4) holds, $u_{C}^{\prime}>0, u_{C}^{\prime \prime}>0$ and assumptions WI and WII hold. The functional form in (4) is quite different from expected utility theory. However, the two models share a related axiomatic foundation and the Kreps and Porteus (1978) model is commonly viewed as a natural extension of expected utility theory. It follows that Calvinists' preferences are compatible with standard axioms and decision theoretic models in economics. Our perspective of Calvinism as a rational system of belief and action is congruent with Weber's view that Calvinists' doctrines are uniquely rational in the sense that, once their premises are accepted, they contain no inner contradictions.

Unlike Protestant agents, the utility functions of Calvinists are based on religious doctrines. Yet, formally, they both share the $K U J$ feature that an increase in aggregate wealth and consumption produces a negative externality. ${ }^{11}$ For Calvinists, increases in aggregate wealth decreases the informativeness of the signs of grace.

\footnotetext{
${ }^{10}$ The Recursive Expected Utility model of Kreps and Porteus (1978) has formed the basis of several established frameworks. See, for instance, Epstein-Zin (1989). The standard REU representation is more complex than the one we use. If only two outcomes have positive probability then preferences for early resolution can be reduced to the simpler function that we use (this is shown in the Appendix). So, our representation is compatible with a broad class of models.

${ }^{11}$ Keeping up with Joneses preferences are generally associated with notions of envy, jealousy, or, to some degree, conspicuous consumption (see Bagwell and Bernheim (1996) for a model of conspicuous consumption). These sentiments are quite distinct from those typically associated with Calvinism. Conspicuous consumption is chastised by Calvinists, and by ascetic Protestants.
} 
Remark 2. A Calvinist's utility diminishes ex-ante with expected aggregate wealth $E W$ and it diminishes ex-post with realized aggregate wealth $W$.

The mechanism behind this result is driven by information. Ex-ante, the informativeness of individual wealth as a signal of grace is reduced by others' decision to save more. Ex-post, higher aggregate wealth implies higher aggregate shock which, in turn, makes individual signals over grace less positive. We now show that the connection between Calvinism and Protestant ethics is much deeper than their formal $K U J$ features.

\section{The Equivalence Result}

Main Result. Assume R1. The Calvinist and Protestant ethics utility subclasses are identical. That is, $\mathfrak{U}_{P E}=\mathfrak{U}_{C}$.

There is no qualitative distinction between Calvinists and Protestant ethics utility functions from a revealed preference perspective. This results holds in and out of equilibrium and it does not rely on the assumption that each individual consumes his earned wealth in the last period. The same result holds if, say, wealth is taxed and redistributed (i.e., $c_{2}^{i} \neq w^{i}$ ).

The equivalence between Calvinism and Protestant ethics preferences is central in our analysis. It formalizes Weber's thesis of a deep connection between the secular Protestant ethic and the religious dogmas of Calvinism. In particular, the highly tractable utility functions of Protestant ethics given by (3) have foundations based on Weber's ideas. Moreover, these simple utility functions can also provide qualitative insights on Calvinism.

Corollary 1. Given any values of the aggregate variables, a Calvinist works more, saves more and has higher expected wealth than a standard agent.

Calvinists work harder than standard agents because hard work and frugal life is a way to obtain a signal of grace. ${ }^{12}$ Hence, Calvinists produce higher expected wealth than standard agents. Extending our model to a dynamic setting is likely to reveal that the growth rate of an economy of Calvinists is higher than the growth rate of an economy of standard agents. Such a result would be consistent with Weber's thesis that the rise of Calvinism was conducive to economic development.

Weber did not consider preferences such as Keeping up with the Joneses. However, formally, the utility functions of Calvinists have the main features of $K U J$ preferences.

\footnotetext{
${ }^{12}$ Corollaries 1 and 2 do not make use of assumption $\mathbf{R} \mathbf{1}$ and do not require the full force of the main result.
} 
Thus, the qualitative insights obtained under preferences designed to understand secular ongoing economies (e.g., $K U J$ preferences) can be transferred to the economies of the past where dogmas, such as belief in predestination, affected practical living. For example, the negative externality of wealth on signs over grace leads to Pareto inefficiencies (See Dupor and Liu (2003) for a similar conclusion in a model of jealousy).

Corollary 2. The equilibrium outcome of an economy consisting of Calvinists is Pareto inefficient. Calvinists overwork and oversave in equilibrium.

Thus, from a welfare perspective, Calvinists acquire excessive wealth.

$K U J$ is often associated with other-regarding sentiments such as envy. In contrast, Weber maintains that Calvinists experienced a "feeling of unprecedented inner loneliness." For what was most important to a Calvinist, his eternal salvation, he was forced to meet alone a preordained destiny. No priest, Church or sacrament could help him. Psychologically, spiritual isolation is quite different from other-regarding sentiments. Yet, in spite of the psychological differences, there is a similarity in the behavior of Calvinists and $K U J$ agents.

\section{Conclusion}

Modern decision-theoretic tools can be used to formalize Weber's thesis of a connection between Calvinism and secular Protestant ethics. They also show a formal connection between utility functions of Calvinism and preferences used for the examination of current economies such as Keeping up with the Joneses. This result relates the secular economies of today and the economies of the past shaped by religious premises. We hope that these results will motivate the use of decision theory for understanding the social consequences of other religious, philosophical, and metaphysical concepts. Such efforts could move the interpretative analysis of faith into the realm of positive inquiry, based on elementary properties of behavior. 


\section{Appendix}

\section{Notation}

Below, we use the notation $s^{i}-S$ and $\Delta s^{i} \equiv s^{i}-S$ interchangeably, and we use $w^{i}-W$ and $\Delta w^{i} \equiv w^{i}-W$. We also use the notation $[-f(\bar{l}), f(\bar{l})]$ and $[\Delta \underline{s}, \Delta \bar{s}]$ interchangeably, where $\Delta \underline{s}=-f(\bar{l})$ and $\Delta \bar{s}=f(\bar{l})$.

Recall, in the proofs that follow, that the probability of shocks $\theta$ and $\gamma^{i}$ are not a function of individual's choices; hence we write $q\left(\gamma^{i}=\gamma\right)$ and not $q\left(\gamma^{i}=\gamma \mid s^{i}, S, \ldots\right)$ without loss, and similarly for $\theta$.

We also note, as discussed in the text, that the Kreps-Porteus utility representation can be written as function $E u_{C}\left(p\left(g^{i}=g \mid \gamma^{i}, s^{i}-S\right)\right)$ when there are only two attainable states of the world. The standard Kreps-Porteus representation for two periods is

$$
E u_{C, e}\left(u_{C, l}^{-1}\left(p\left(g^{i}=g \mid \gamma^{i}, s^{i}-S\right) u_{C, l}\left(g^{i}=g\right)+\left(1-p\left(g^{i}=g \mid \gamma^{i}, s^{i}-S\right)\right) u_{C, l}\left(g^{i}=n\right)\right)\right)
$$

where $u_{C, e}$ is the utility associated with the first stage, and $u_{C, l}$ is the utility associated with the second stage. Normalizing $u_{C, l}\left(g^{i}=g\right)=1$ and $u_{C, l}\left(g^{i}=n\right)=0$, the representation $E u_{C}\left(p\left(g^{i}=g \mid \gamma^{i}, s^{i}-S\right)\right)$ follows immediately, defining $u_{C} \equiv u_{C, e} \circ u_{C, l}^{-1}$. Moreover, the assumption of a preference for early resolution of uncertainty in the Kreps-Porteus representation requires that $u_{C}=u_{C, e} \circ u_{C, l}^{-1}$ be convex, as we have assumed.

\section{Proofs}

Remark 3. Given any values of the aggregate variables, any Protestant ethics agent works more, saves more and has higher expected wealth than a standard agent.

Proof. Letting $\mu \in[0,1]$, we consider the following maximization problem.

$$
U^{i}=\left[u\left(c_{1}^{i}\right)+\beta E u\left(c_{2}^{i}\right)-d\left(l^{i}\right)\right]+\mu E v\left(w^{i}-W\right)
$$

s.t. $[\mathrm{BC}]$ :

$$
\begin{aligned}
& c_{1}^{i}=f\left(l^{i}\right)-s^{i} ; w^{i}=\left(s^{i}+\gamma^{i} \theta\right)(1+r) \\
& c_{2}^{i}=w^{i}, 0 \leq l^{i} \leq \bar{l} ; 0 \leq s^{i} \leq f\left(l^{i}\right) .
\end{aligned}
$$

$\mu=0$ corresponds to the standard agent's problem, and $\mu=1$ corresponds to the Protestant ethics agent problem. We proceed by using the implicit function theorem, and show that $\frac{d s^{*}(S, L)}{d \mu}>0$ and $\frac{d l^{*}(S, L)}{d \mu}>0$, where $s^{*}(S, L), l^{*}(S, L)$ are the optimal savings and 
labor chosen by agent $i$, given aggregate variables $S$ and $L$ (note that $S$ and $L$ completely characterize the ex-ante aggregate decisions). The first order conditions with respect to $s^{i}$ and $l^{i}$ are:

\section{First order conditions}

$$
\begin{aligned}
F_{s} & \equiv-u^{\prime}\left(c_{1}^{i}\right)+\beta(1+r) E u^{\prime}\left(c_{2}^{i}\right)+\mu(1+r) E v^{\prime}\left(w^{i}-W\right)=0 \\
F_{l} & \equiv u^{\prime}\left(c_{1}^{i}\right) f^{\prime}\left(l^{i}\right)-d^{\prime}\left(l^{i}\right)=0 .
\end{aligned}
$$

The Hessian is then $\left[\begin{array}{cc}F_{s s} & F_{l s} \\ F_{l s} & F_{l l}\end{array}\right]$, where

$$
\begin{aligned}
F_{s s} & \equiv u^{\prime \prime}\left(c_{1}^{i}\right)+\beta(1+r)^{2} E u^{\prime \prime}\left(c_{2}^{2}\right)+\mu(1+r)^{2} E v^{\prime \prime}\left(w^{i}-W\right) \\
F_{l s} & \equiv-u^{\prime \prime}\left(c_{1}^{i}\right) f^{\prime}\left(l^{i}\right) \\
F_{l l} & \equiv u^{\prime \prime}\left(c_{1}^{i}\right)\left(f^{\prime}\left(l^{i}\right)\right)^{2}+f^{\prime \prime}\left(l^{i}\right) u^{\prime}\left(c_{1}^{i}\right)-d^{\prime \prime}\left(l^{i}\right) .
\end{aligned}
$$

Applying the implicit function theorem, we have:

$$
\begin{aligned}
{\left[\begin{array}{c}
\frac{d s^{*}(S, L)}{d \mu} \\
\frac{d l^{*}(S, L)}{d \mu}
\end{array}\right] } & =-\frac{1}{\triangle}\left[\begin{array}{cc}
F_{l l} & -F_{l s} \\
-F_{l s} & F_{s s}
\end{array}\right]\left[\begin{array}{c}
\frac{d F_{s}}{d \mu} \\
0
\end{array}\right] \\
& =\frac{1}{\triangle}\left[\begin{array}{c}
-F_{l l} \frac{d F_{s}}{d \mu} \\
F_{l s} \frac{d F_{s}}{d \mu}
\end{array}\right]=\frac{1}{\triangle}\left[\begin{array}{c}
-(1+r) F_{l l} E v^{\prime}\left(w^{i}-W\right) \\
(1+r) F_{l s} E v^{\prime}\left(w^{i}-W\right)
\end{array}\right]
\end{aligned}
$$

where $\triangle$ is the determinant of the Hessian.

Given our assumptions, the Hessian is negative definite, and therefore (as it is $2 \times 2$ ) $\triangle>0$. It is clear that $F_{l l}<0$, that $F_{l s}>0$ and that $E v^{\prime}\left(w^{i}-W\right)>0$, since $u^{\prime \prime}\left(c_{1}^{i}\right)<0$, $f^{\prime \prime}\left(l^{i}\right)<0, u^{\prime}\left(c_{1}^{i}\right)>0, d^{\prime \prime}\left(l^{i}\right)>0$ and $v^{\prime}\left(w^{i}-W\right)>0$. It follows that $\frac{d s^{*}(S, L)}{d \mu}>0$ and that $\frac{d l^{*}(S, L)}{d \mu}>0$. It is then immediate that $\frac{d E w^{*}(S, L)}{d \mu}=(1+r) \frac{d s^{*}(S, L)}{d \mu}>0$. Finally, since the result holds for any aggregate variables $S$ and $L$, this concludes the proof.

The following lemma will be used in the results that follow.

Lemma 1. For a Calvinist agent with function $V^{i}=E u_{C}\left(p\left(g^{i}=g \mid \gamma^{i}, s^{i}-S\right)\right)$, define function $\tilde{u}_{C}:[\Delta \underline{s}, \Delta \bar{s}] \rightarrow \mathbb{R}$ to be $\tilde{u}_{C}\left(s^{i}-S\right)=E u_{C}\left(p\left(g^{i}=g \mid \gamma^{i}, s^{i}-S\right)\right)$, for all $s^{i}-S \in$ $[\Delta \underline{s}, \Delta \bar{s}]$. Then $\tilde{u}_{C}^{\prime}>0$. 
Proof. By assumption WII, the Calvinist's signal over grace becomes more informative as $s^{i}-S$ increases. While this can be proven directly, we instead apply Proposition 1 of Grant, Kajii and Polak (1998). Specifically, by statement (V) of the proposition, SAIL holds, and the result then follows from the equivalence of statements $\mathrm{A}$ and $\mathrm{B}$ of the same proposition.

Remark 4. A Calvinist's utility diminishes ex-ante with expected aggregate wealth EW and it diminishes ex-post with realized aggregate wealth $W$.

Proof. By Lemma 1, the Calvinist's utility $U^{i}=\left[u\left(c_{1}^{i}\right)+\beta E u\left(c_{2}^{i}\right)-d\left(l^{i}\right)\right]+E u_{C}\left(p\left(g^{i}=\right.\right.$ $\left.\left.g \mid \gamma^{i}, s^{i}-S\right)\right)=\left[u\left(c_{1}^{i}\right)+\beta E u\left(c_{2}^{i}\right)-d\left(l^{i}\right)\right]+\tilde{u}_{C}\left(s^{i}-S\right)$ for $\tilde{u}_{C}>0$. It is then immediate that $\frac{d U^{i}}{d E W}=\frac{d U^{i}}{d E S}=-\tilde{u}_{C}\left(s^{i}-S\right)^{\prime}<0$. The Calvinist's utility therefore diminishes ex-ante with $E W$.

We now show that the Calvinist's utility diminishes ex-post. Since ex-post wealth $w^{i}=$ $\left(s^{i}+\gamma^{i} \theta\right)(1+r)$ and $W=(S+\theta)(1+r)$, it follows that:

$$
\gamma^{i}=\frac{\frac{w^{i}}{1+r}-s^{i}}{\theta}=\frac{\frac{w^{i}}{1+r}-s^{i}}{\frac{W}{1+r}-S}=\frac{w^{i}-s^{i}(1+r)}{W-S(1+r)}
$$

Hence, a higher $W$ implies a lower $\gamma^{i}$. By assumption WI (MLRP), it is immediate that a lower $\gamma^{i}$ leads to a more negative signal of grace $g^{i}: \frac{p\left(\gamma^{i} \mid G^{i}=g, \Delta s^{i}\right)}{p\left(\gamma^{i} \mid G^{i}=b, \Delta s^{i}\right)}>\frac{p\left(\gamma^{i} \mid G^{i}=g, \Delta s^{i}\right)}{p\left(\gamma^{i} \mid G^{i}=b, \Delta s^{i}\right)}$ if $\gamma^{i}>\gamma^{i}$ (for all $\left.\Delta s^{i} \in\left[\Delta \underline{s}^{i}, \Delta \bar{s}^{i}\right]\right)$ is trivially equivalent, in this setting, to $p\left(G^{i}=g \mid \gamma^{i}, \Delta s^{i}\right)>$ $p\left(G^{i}=g \mid \gamma^{i}, \Delta s^{i}\right)$ for $\gamma^{i}>\gamma^{i}$ (for all $\left.\Delta s^{i} \in\left[\Delta \underline{s}^{i}, \Delta \bar{s}^{i}\right]\right)$ :

$$
\begin{aligned}
& \frac{p\left(\gamma^{i} \mid g^{i}=g, \Delta s^{i}\right)}{p\left(\gamma^{i} \mid g^{i}=n, \Delta s^{i}\right)}>\frac{p\left(\gamma^{\prime i} \mid g^{i}=g, \Delta s^{i}\right)}{p\left(\gamma^{\prime i} \mid g^{i}=n, \Delta s^{i}\right)} \\
& \Leftrightarrow \frac{p\left(g^{i}=g \mid \gamma^{i}, \Delta s^{i}\right) p\left(\gamma^{i}\right)\left(1-p_{g}\right)}{\left(1-p\left(g^{i}=g\left|\gamma^{i}\right|, \Delta s^{i}\right)\right) p\left(\gamma^{i}\right) p_{g}}>\frac{p\left(g^{i}=g \mid \gamma^{\prime i}, \Delta s^{i}\right) p\left(\gamma^{\prime i}\right)\left(1-p_{g}\right)}{\left(1-p\left(g^{i}=g\left|\gamma^{\prime i}\right|, \Delta s^{i}\right)\right) p\left(\gamma^{\prime i}\right) p_{g}} \\
& \Leftrightarrow p\left(g^{i}=g \mid \gamma^{i}, \Delta s^{i}\right)\left(1-p\left(g^{i}=g \mid \gamma^{\prime i}, \Delta s^{i}\right)\right)>p\left(g^{i}=g \mid \gamma^{\prime i}, \Delta s^{i}\right)\left(1-p\left(G^{i}=g \mid \gamma^{i}, \Delta s^{i}\right)\right) \\
& \Leftrightarrow p\left(g^{i}=g \mid \gamma^{i}, \Delta s^{i}\right)>p\left(g^{i}=g \mid \gamma^{\prime i}, \Delta s^{i}\right) .
\end{aligned}
$$

Hence, $p\left(g^{i}=g \mid \gamma^{i}, s^{i}-S\right)$ is lower for a higher $W$, which in turn implies that $u_{C}\left(\left(p\left(g^{i}=\right.\right.\right.$ $\left.\left.g\left(\gamma^{i}, s^{i}-S\right)\right)\right)$ is lower. Since no other term in the utility function is affected, this concludes the proof.

Main Result. Assume $\boldsymbol{R} 1$. The Calvinist and Protestant ethics utility subclasses are identical. That is, $\mathfrak{U}_{P E}=\mathfrak{U}_{C}$. 
Proof. We first show that any Protestant ethic agent falls within the Calvinist utility subclass $\mathfrak{U}_{C}$, and then show that any Calvinist agent falls within the Protestant ethic subclass.

\section{Protestant ethics agent falls within Calvinist subclass}

Take any Protestant agent function $U^{i}=E v\left(w^{i}-W\right)$, with $v^{\prime}>0$. We show that it can written as a function $E u_{C}\left(p\left(g^{i}=g \mid \gamma^{i}, s^{i}-S\right)\right)$ where $u_{C}$ is strictly increasing and convex. We then such that the following conditions hold: 1) $p\left(g^{i}=g \mid \gamma^{i}, s^{i}-S\right) \in[0,1]$, 2)the Bayesian assumption holds, 3) assumption W1 holds and 3) assumption WII holds.

We first define function $\tilde{v}:[\Delta \underline{s}, \Delta \bar{s}] \Rightarrow \mathbb{R}$ as follows:

$$
\begin{gathered}
\tilde{v}\left(\Delta s^{i}\right) \equiv E v_{W}\left(w^{i}-W\right)=\sum_{\gamma^{i}, \theta} q_{\gamma}\left(\gamma^{i}\right) q_{\theta}(\theta) v\left(w^{i}-W\right) \\
=\sum_{\gamma^{i}, \theta} q_{\gamma}\left(\gamma^{i}\right) q_{\theta}(\theta) v\left(\left(\left(s^{i}-S\right)+\theta\left(\gamma^{i}-1\right)\right)(1+r)\right) .
\end{gathered}
$$

Note that $\tilde{v}$ is well defined and strictly increasing in $\Delta s^{i}$, since $v$ is strictly increasing everywhere.

We now proceed by construction. We specifically define a function $u_{C}$ and an updating rule, and show first that $E u_{C}\left(p\left(G^{i}=g \mid \Delta s^{i}, \gamma^{i}\right)\right)$ is exactly equivalent to function $\tilde{v}\left(\Delta s^{i}\right)$ for all $\Delta s^{i} \in[\Delta \underline{s}, \Delta \bar{s}]$. We then show that all the properties required by the Calvinist problem are satisfied.

\section{Preferences $u_{C}$}

We define $u_{C}$ to be $u_{C}(\cdot)=a\left((\cdot)^{2}-p_{g}^{2}\right)+\tilde{v}(\Delta \underline{s})$, where $a>0$, and the agent's prior over $G$ is $p_{g} \in(0,1)$. The requirements that $u_{C}$ be strictly increasing and convex are met.

\section{Belief updating rule}

The agent updates his prior as follows. First, partition the set of $\gamma$ into $\left\{\gamma_{1, h}, \ldots, \gamma_{n_{h}, h}\right\}$ and $\left\{\gamma_{1, l}, \ldots, \gamma_{n_{l}, l}\right\}$, where $1<\gamma_{1, h}<\ldots<\gamma_{n_{h}, h}$, and $1 \geq \gamma_{1, l}>\ldots \gamma_{n_{l}, l}$. Both sets are well-defined and non-empty. The agent updates his prior, for any $\Delta s^{i}$, according to $p\left(G^{i}=g \mid \gamma^{i}, \Delta s^{i}\right)=p_{g}+f\left(\Delta s^{i}, \gamma^{i}\right)$, where $f$ is defined as follows. We first define $f\left(\Delta s^{i}, \gamma_{n_{h}, h}\right)$. 


$$
f\left(\Delta s^{i}, \gamma_{n_{h}, h}\right)=\left(\frac{\tilde{v}\left(\Delta s^{i}\right)-\tilde{v}(\Delta \underline{s})}{a\left(q\left(\gamma_{n_{h}, h}\right)+\epsilon^{2} \sum_{j=1}^{n_{h}-1} q\left(\gamma_{j, h}\right) j^{2}+d^{2}\left(q\left(\gamma_{n_{l}, l}\right)+\epsilon^{2} \sum_{j=1}^{n_{l}-1} q\left(\gamma_{j, l}\right) j^{2}\right)\right)}\right)^{1 / 2}
$$

where $\epsilon$ is an arbitrarily small positive constant (specifically, $\epsilon \in\left(0, \min \left\{\left(n_{l}-1\right)^{-1},\left(n_{h}-\right.\right.\right.$ $\left.\left.1)^{-1}\right\}\right)$ ), and:

$$
d=\frac{\left(q\left(\gamma_{n_{h}, h}\right)+\epsilon \sum_{j=1}^{n_{h}-1} q\left(\gamma_{j, h}\right) j\right)}{\left(q\left(\gamma_{n_{l}, l}\right)+\epsilon \sum_{j=1}^{n_{l}-1} q\left(\gamma_{j, l}\right) j\right)}
$$

For other values of $\gamma^{i}, f$ is defined as follows:

$$
f\left(\triangle s^{i}, \gamma^{i}\right)= \begin{cases}j \epsilon f\left(\Delta s^{i}, \gamma_{n_{h}, h}\right) & \text { if } \gamma^{i}=\gamma_{j, h}, j \in\left\{1, . ., n_{h}-1\right\} \\ -d f\left(\Delta s^{i}, \gamma_{n_{h}, h}\right) & \text { if } \gamma^{i}=\gamma_{n_{l}, l} \\ j \epsilon f\left(\triangle s^{i}, \gamma_{n_{l}, l}\right) & \text { if } \gamma^{i}=\gamma_{j, h}, j \in\left\{1, . ., n_{l}-1\right\}\end{cases}
$$

Moreover, assume that $a$ is high enough that $p_{g}+f\left(\Delta s^{i}, \gamma^{i}\right) \in(0,1)$ for all values of $\Delta s^{i} \in$ $[\Delta \underline{s}, \Delta \bar{s}]$ and attainable values of $\gamma^{i}$. Notice that such a value exists, since $f\left(\Delta \bar{s}^{i}, \gamma_{n_{h}, h}\right)$ and $f\left(\Delta \bar{s}^{i}, \gamma_{n_{l}, l}\right)$, the maximum and minimum values, respectively, of $f$, go to zero as $a$ goes to infinity. Note that the signal received by the agent is only a function of $\Delta s^{i}$ and $\gamma^{i}$, and not of aggregate shock $\theta$. We also point out that constructing a signal to obtain the linear structure $p_{g}+f\left(\Delta s^{i}, \gamma^{i}\right)$ can always be achieved (in particular, it suffices to let $\frac{p\left(\gamma^{i} \mid g, \Delta s^{i}\right)}{p\left(\gamma^{i} \mid n, \Delta s^{i}\right)}=\frac{\left(p_{g}+f\right)\left(1-p_{g}\right)}{p_{g}\left(1-p_{g}-f\right)}$, which can always be achieved for sufficiently high $p_{g} \in(0,1)$, which we assume).

We first show that this construction of $f$ satisfies all the required properties on the signal received by the Calvinist agent, and then proceed to show that $u_{C}$ satisfies our assumptions as well. 


\section{Properties of the signal}

1. $p\left(G^{i}=g \mid \gamma^{i}, \Delta s^{i}\right) \in[0,1]$ for all $\Delta s^{i}$, since $p\left(G^{i}=g \mid \gamma^{i}, \Delta s^{i}\right)$ is a probability. This is true by construction, since $a$ has been chosen to be high enough for $p_{g}+f\left(\Delta s^{i}, \gamma^{i}\right)=$ $p\left(G^{i}=g \mid \gamma^{i}, \Delta s^{i}\right)$ to be in $(0,1)$.

2. The Bayesian assumption holds: this is true, since for all $\triangle s^{i} \in[\Delta \underline{s}, \Delta \bar{s}]$,

$$
\begin{aligned}
\sum_{\gamma^{i}} q\left(\gamma_{i}\right)\left(p_{g}+f\left(\Delta s^{i}, \gamma^{i}\right)\right)=p_{g}+\sum_{\gamma^{i}} q\left(\gamma_{i}\right) f\left(\Delta s^{i}, \gamma^{i}\right) \\
=p_{g}+q\left(\gamma_{n_{h}, h}\right) f\left(\Delta s^{i}, \gamma_{n_{h}, h}\right)+q\left(\gamma_{n_{l}, l}\right) f\left(\Delta s^{i}, \gamma_{n_{l}, l}\right) \\
\quad+\epsilon\left(\sum_{j=1}^{n_{h}-1} q\left(\gamma_{j, h}\right) j f\left(\Delta s^{i}, \gamma_{n_{h}, h}\right)+\sum_{j=1}^{n_{l}-1} q\left(\gamma_{j, l}\right) j f\left(\Delta s^{i}, \gamma_{n_{l}, l}\right)\right) \\
=p_{g}+f\left(\Delta s^{i}, \gamma_{n_{h}, h}\right)\left(q\left(\gamma_{n_{h}, h}\right)-d q\left(\gamma_{n_{l}, l}\right)+\epsilon\left(\sum_{j=1}^{n_{h}-1} q\left(\gamma_{j, h}\right) j-d \sum_{j=1}^{n_{l}-1} q\left(\gamma_{j, l}\right) j\right)\right) \\
=p_{g}+f\left(\Delta s^{i}, \gamma_{n_{h}, h}\right)\left(q\left(\gamma_{n_{h}, h}\right)+\epsilon \sum_{j=1}^{n_{h}-1} q\left(\gamma_{j, h}\right) j-d\left(q\left(\gamma_{n_{l}, l}\right)+\epsilon \sum_{j=1}^{n_{l}-1} q\left(\gamma_{j, l}\right) j\right)\right) \\
=p_{g}+f\left(\Delta s^{i}, \gamma_{n_{h}, h}\right)\left(q\left(\gamma_{n_{h}, h}\right)+\epsilon \sum_{j=1}^{n_{h}-1} q\left(\gamma_{j, h}\right) j-\left(q\left(\gamma_{n_{h}, h}\right)+\epsilon \sum_{j=1}^{n_{h}-1} q\left(\gamma_{j, h}\right) j\right)\right)
\end{aligned}
$$

3. Assumption WI (MLRP), for which it suffices to show that a higher $\gamma^{i}$ leads to a more positive signal of state of grace $G^{i}$. Specifically: the condition $\frac{p\left(\gamma^{i} \mid G^{i}=g, \Delta s^{i}\right)}{p\left(\gamma^{i} \mid G^{i}=b, \Delta s^{i}\right)}>$ $\frac{p\left(\gamma^{i} \mid G^{i}=g, \Delta s^{i}\right)}{p\left(\gamma^{i} \mid G^{i}=b, \Delta s^{i}\right)}$ if $\gamma^{i}>\gamma^{\prime i}$ (for all $\Delta s^{i} \in\left[\Delta \underline{s}^{i}, \Delta \bar{s}^{i}\right]$ ) is trivially equivalent, in this setting, to $p\left(G^{i}=g \mid \gamma^{i}, \Delta s^{i}\right)>p\left(G^{i}=g \mid \gamma^{\prime i}, \Delta s^{i}\right)$ for $\gamma^{i}>\gamma^{\prime i}$ (for all $\Delta s^{i} \in\left[\Delta \underline{s}^{i}, \Delta \bar{s}^{i}\right]$ ), as shown in Remark 1.

To prove that a higher $\gamma^{i}$ leads to a more positive signal of grace, note first that $f\left(\Delta \gamma^{i}, \Delta s^{i}\right)$ increases in $\gamma^{i}$ for all $\Delta s^{i} \in[\Delta \underline{s}, \Delta \bar{s}]$. Hence, $p\left(G^{i}=g \mid \gamma^{\prime i}, \Delta s^{i}\right)=$ $p_{g}+f\left(\Delta \gamma^{i}, \Delta s^{i}\right)>p_{g}+f\left(\Delta \gamma^{i}, \Delta s^{i}\right)=p\left(G^{i}=g \mid \gamma^{\prime i}, \Delta s^{i}\right)$ for $\gamma^{i}>\gamma^{\prime i}$, for all $\Delta s^{i} \in[\Delta \underline{s}, \Delta \bar{s}]$.

4. Assumption WII, that for higher $\Delta s^{i}$, the agent receives a more informative signal, in the Blackwell sense. To show that this property holds, note first that the lottery characterized by $\left\{q\left(\gamma_{1}\right), f\left(\Delta \gamma_{1}, \Delta s^{i}\right), \ldots, q(\bar{\gamma}), f\left(\Delta \bar{\gamma}, \Delta s^{i}\right)\right\}$ is a mean-preserving spread of the lottery characterized by $\left\{q\left(\gamma_{1}\right), f\left(\Delta \gamma_{1}, \Delta s^{i}\right), \ldots, q(\bar{\gamma}), f\left(\Delta \bar{\gamma}, \Delta s^{i i}\right)\right\}$, 
where $\Delta s^{i}>\Delta s^{i}$. As there are only two states of the world, it follows immediately that assumption WII holds (see, for instance, Ganuza and Penalva (2010), proposition 3: the signals are ranked by integral precision, which is equivalent to Blackwell informativeness in a context of dichotomies).

We now show that $E u_{C}\left(p\left(G^{i}=g \mid \Delta s^{i}, \gamma^{i}\right)\right.$ is exactly equivalent to function $\tilde{v}\left(\Delta s^{i}\right)$ for all $\Delta s^{i} \in[\Delta \underline{s}, \Delta \bar{s}]:$

$$
\begin{aligned}
& E u_{C}\left(p\left(G^{i}=g \mid \Delta s^{i}, \gamma^{i}\right)\right)=\sum_{\gamma^{i}} q\left(\gamma^{i}\right)\left(a\left(\left(p_{g}+f\left(\Delta s^{i}, \gamma^{i}\right)\right)^{2}-p_{g}^{2}\right)+\tilde{v}(\Delta \underline{s})\right) \\
& \begin{array}{r}
\sum_{\gamma^{i}} a q\left(\gamma^{i}\right) f\left(\Delta s^{i}, \gamma^{i}\right)^{2}-2 a p_{g}\left(\sum_{\gamma^{i}} q\left(\gamma^{i}\right) f\left(\Delta s^{i}, \gamma^{i}\right)\right)+\tilde{v}(\Delta \underline{s})=\sum_{\gamma^{i}} a q\left(\gamma^{i}\right) f\left(\Delta s^{i}, \gamma^{i}\right)^{2}+\tilde{v}(\Delta \underline{s}) \\
=a\left(q\left(\gamma_{n_{h}, h}\right) f\left(\Delta s^{i}, \gamma_{n_{h}, h}\right)^{2}+\sum_{j=1}^{n_{h}-1} q\left(\gamma_{j, h}\right)\left(\epsilon j f\left(\Delta s^{i}, \gamma_{n_{h}, h}\right)\right)^{2}+q\left(\gamma_{n_{l}, l}\right) f\left(\Delta s^{i}, \gamma_{n_{l}, l}\right)^{2}\right. \\
\left.+\sum_{j=1}^{n_{l}-1} q\left(\gamma_{j, l}\right)\left(\epsilon j f\left(\Delta s^{i}, \gamma_{n_{l}, l}\right)\right)^{2}\right)+\tilde{v}(\Delta \underline{s}) \\
=a f\left(\Delta s^{i}, \gamma_{n_{h}, h}\right)^{2}\left(q\left(\gamma_{n_{h}, h}\right)+\epsilon^{2} \sum_{j=1}^{n_{h}-1} q\left(\gamma_{j, h}\right) j^{2}+d^{2}\left(q\left(\gamma_{n_{l}, l}\right)+\epsilon^{2} \sum_{j=1}^{n_{l}-1} q\left(\gamma_{j, l}\right) j^{2}\right)\right)+\tilde{v}(\Delta \underline{s}) \\
=\tilde{v}\left(\Delta s^{i}\right)-\tilde{v}(\Delta \underline{s})+\tilde{v}(\Delta \underline{s})=\tilde{v}\left(\Delta s^{i}\right) .
\end{array}
\end{aligned}
$$

Note that we have used that $\left.\sum_{\gamma^{i}} q\left(\gamma^{i}\right) f\left(\Delta s^{i}, \gamma^{i}\right)\right)=0$, as had been shown in the proof that the Bayesian assumption holds (step 2 above). All the properties are satisfied, which completes this direction of the proof. We now turn to the second part of the proof.

\section{Calvinist agent falls within Protestant subclass}

We proceed by construction. First, we apply Lemma 1, and write Calvinist function $V^{i}=E u_{C}\left(p\left(g^{i}=g \mid \gamma^{i}, \Delta s^{i}\right)\right)$ as strictly increasing function $\tilde{u}_{C}\left(\Delta s^{i}\right)=E u_{C}\left(p\left(g^{i}=\right.\right.$ $\left.\left.g \mid \gamma^{i}, \Delta s^{i}\right)\right)$, for all $\Delta s^{i} \in[\Delta \underline{s}, \Delta \bar{s}]$. We construct a function $\tilde{v}:[(\Delta \underline{s}-\bar{\theta}(1-\underline{\gamma}))(1+$ $r),(\Delta \bar{s}+\bar{\theta}(\bar{\gamma}-1))(1+r)] \rightarrow \mathbb{R}$ such that $E v\left(w^{i}-W \mid \Delta s^{i}\right)=\tilde{u}_{C}\left(\Delta s^{i}\right)$ for all $\Delta s^{i} \in$ $[\Delta \underline{s}, \Delta \bar{s}]$. We then show that $v^{\prime}>0$ everywhere.

We first define $f$ to be an arbitrary smooth and strictly increasing function on the compact interval $[(\Delta \bar{s}-\bar{\theta}(1-\underline{\gamma}))(1+r),(\Delta \bar{s}+\bar{\theta}(\bar{\gamma}-1))(1+r)]$, where the maximum derivative of $f$ on this interval is $f_{\max }^{\prime}<\infty$. We write the lower bound of the interval in this manner (instead of $(\Delta \bar{s}+\bar{\theta}(\underline{\gamma}-1))(1+r))$ as a reminder that $\underline{\gamma}<1$. We define, on this interval, 
function

$$
v\left(\Delta w^{i}\right)=a f\left(\triangle w^{i}\right)+b
$$

where $a>0$, and constant $b$ is chosen such that $\operatorname{Ev}\left(\Delta w^{i} \mid \Delta \bar{s}\right)=\tilde{u}_{C}(\Delta \bar{s})$. Specifically, let $b=a\left(\tilde{u}_{C}(\Delta \bar{s})-\sum_{\gamma^{i}, \theta} f\left(\left(\Delta \bar{s}+\theta\left(\gamma^{i}-1\right)\right)(1+r)\right)\right)$.

Consider any $\Delta \underline{s}^{i} \leq \Delta s^{i}<\Delta \bar{s}^{i}$. Then, we require that $E v\left(\Delta w \mid \Delta s^{i}\right)=\tilde{u}_{C}\left(\Delta s^{i}\right)$. That is, we require that

$$
\begin{aligned}
& E v\left(\Delta w \mid \Delta s^{i}\right)=\sum_{\gamma^{i}, \theta} p(\theta) p\left(\gamma^{i}\right) v\left(\left(\Delta s^{i}+\theta\left(\gamma^{i}-1\right)\right)(1+r)\right) \\
& =p(\bar{\theta}) p(\underline{\gamma}) v\left(\left(\Delta s^{i}-\bar{\theta}(1-\underline{\gamma})\right)(1+r)\right)+\sum_{\gamma^{i} \neq \underline{\gamma} \bigcup \theta \neq \bar{\theta}} p(\theta) p\left(\gamma^{i}\right) v\left(\left(\Delta s^{i}+\theta\left(\gamma^{i}-1\right)\right)(1+r)\right) \\
& =p(\bar{\theta}) p(\underline{\gamma}) v\left(\left(\Delta s^{i}-\bar{\theta}(1-\underline{\gamma})\right)(1+r)\right)+\sum_{\gamma^{i} \neq \underline{\gamma} \bigcup \theta \neq \bar{\theta}} p(\theta) p\left(\gamma^{i}\right)\left(a f\left(\left(\Delta s^{i}+\theta\left(\gamma^{i}-1\right)\right)(1+r)\right)+b\right) \\
& =\tilde{u}_{C}\left(\Delta s^{i}\right)
\end{aligned}
$$

where we have used, for the second term of line 11, that $v$ has already been defined in (8) on that range. We note, for $\gamma^{i} \neq \underline{\gamma} \cup \theta \neq \bar{\theta}$, that $\left(\Delta s^{i}+\theta\left(\gamma^{i}-1\right)\right)(1+r) \in$ $[(\Delta \bar{s}-\bar{\theta}(1-\underline{\gamma}))(1+r),(\Delta \bar{s}+\bar{\theta}(\bar{\gamma}-1))(\overline{1}+r)]$ follows from assumption R1. (We implicitly assume that there is a $\gamma \in\{\underline{\gamma}, \ldots, \bar{\gamma}\}$ such that $1 \geq \gamma>\underline{\gamma}$; if we do not make this implicit assumption, then $\mathbf{R} \mathbf{1}$ would instead be written: $\underline{\gamma}<((\bar{\theta}-\theta)+\theta \gamma-(\Delta \bar{s}-\Delta \underline{s})) / \bar{\theta}$ for all $\gamma \neq \underline{\gamma} \cup \theta \neq \bar{\theta}$, where $\gamma \in\{\underline{\gamma}, \ldots, \bar{\gamma}\}$ and $\theta \in\{\underline{\theta}, \ldots, \bar{\theta}\}$. Note that in all cases, assumption $\mathbf{R} 1$ can be interpreted to mean that $\bar{\theta}$ must be sufficiently high. That is, we can rewrite the latter condition as: $\bar{\theta}>((\Delta \bar{s}-\Delta \underline{s})-\theta(\gamma-1)) /(1-\underline{\gamma}))$.)

To see this, let $\check{\gamma}=\min \{\{\underline{\gamma}, \ldots, \bar{\gamma}\} \backslash\{\underline{\gamma}\}\}$, and note that $\bar{\theta}(\check{\gamma}-1) \leq \theta\left(\gamma^{i}-1\right)$ for all $\gamma^{i} \neq \underline{\gamma} \cup \theta \neq \bar{\theta}$, since $\check{\gamma}<1$. Then, applying assumption R1:

$$
\begin{aligned}
\underline{\gamma} & <\check{\gamma}-(\Delta \bar{s}-\Delta \underline{s})) / \bar{\theta} \\
& \Rightarrow \bar{\theta} \underline{\gamma}<\bar{\theta} \check{\gamma}-(\Delta \bar{s}-\Delta \underline{s})) \\
& \Rightarrow \Delta \bar{s}+\bar{\theta}(\underline{\gamma}-1)<\Delta \underline{s}+\bar{\theta}(\check{\gamma}-1) \\
& \Rightarrow(\Delta \bar{s}-\bar{\theta}(1-\underline{\gamma}))(1+r)<(\Delta \underline{s}+\bar{\theta}(\check{\gamma}-1))(1+r) \\
& \Rightarrow(\Delta \bar{s}-\bar{\theta}(1-\underline{\gamma}))(1+r)<\left(\Delta \underline{s}+\theta\left(\gamma^{i}-1\right)\right)(1+r) \\
& \Rightarrow(\Delta \bar{s}-\bar{\theta}(1-\underline{\gamma}))(1+r)<\left(\Delta s^{i}+\theta\left(\gamma^{i}-1\right)\right)(1+r)
\end{aligned}
$$


for all $\gamma^{i} \neq \underline{\gamma} \cup \theta \neq \bar{\theta}$

While we have not yet explicitly defined $v$ for $\left(\Delta s^{i}-\bar{\theta}(1-\underline{\gamma})\right)(1+r)$, it is clear from (11) and (12) that we are fully constrained in the specification of $v$ on this remaining interval. Specifically,

$v\left(\left(\Delta s^{i}-\bar{\theta}(1-\underline{\gamma})\right)(1+r)\right)=\left(\tilde{u}_{C}\left(\Delta s^{i}\right)-\sum_{\gamma^{i} \neq \bar{\gamma} \bigcup \theta \neq \bar{\theta}} p(\theta) p\left(\gamma^{i}\right)\left(a f\left(\left(\Delta s^{i}+\theta\left(\gamma^{i}-1\right)\right)(1+r)\right)+b\right)\right) /(p(\bar{\theta}) p(\underline{\gamma}))$

Using (14), we define $v$ as a function of $\Delta w^{i}$, i.e. letting $\Delta w^{i}=\left(\Delta s^{i}-\bar{\theta}(1-\underline{\gamma})\right)(1+r)$, we have

$v\left(\Delta w^{i}\right)=\left(\tilde{u}_{C}\left(\Delta w^{i} /(1+r)+\bar{\theta}(1-\underline{\gamma})\right)-\sum_{\gamma^{i} \neq \underline{\gamma} \cup \theta \neq \bar{\theta}} p(\theta) p\left(\gamma^{i}\right)\left(a f\left(\Delta w^{i}+\left(\theta\left(\gamma^{i}-1\right)+\bar{\theta}(1-\underline{\gamma})\right)(1+r)\right)+b\right)\right) /(p(\bar{\theta}) p(\underline{\gamma}))$

We define $v$ according to $(15)$ for all $\Delta w^{i} \in[(\Delta \underline{s}-\bar{\theta}(1-\underline{\gamma}))(1+r),(\Delta \bar{s}-\bar{\theta}(1-\underline{\gamma}))(1+r))$.

By construction, we therefore have that $E v\left(\Delta w \mid \Delta s^{i}\right)=\tilde{u}_{C}\left(\Delta s^{i}\right)$ everywhere. We now guarantee that $v^{\prime}>0$. First, $v$ is increasing on $[(\Delta \bar{s}-\bar{\theta}(1-\underline{\gamma}))(1+r),(\Delta \bar{s}+\bar{\theta}(\bar{\gamma}-1))(1+$ $r)$ ] by construction. Second, for $\Delta w^{i} \in[(\Delta \underline{s}-\bar{\theta}(1-\underline{\gamma}))(1+r),(\Delta \bar{s}-\bar{\theta}(1-\underline{\gamma}))(1+r))$, the condition $v^{\prime}\left(\Delta w^{i}\right)>0$ is satisfied if:

$\left(\tilde{u}_{C}^{\prime}\left(\Delta w^{i} /(1+r)+\bar{\theta}(1-\underline{\gamma})\right)-\sum_{\gamma^{i} \neq \bar{\gamma} \cup \theta \neq \bar{\theta}} a p(\theta) p\left(\gamma^{i}\right) f^{\prime}\left(\Delta w^{i}+\left(\theta\left(\gamma^{i}-1\right)+\bar{\theta}(1-\underline{\gamma})\right)(1+r)\right)\right) /(p(\bar{\theta}) p(\underline{\gamma}))>0$,

for which it suffices that

$$
\begin{array}{r}
\tilde{u}_{C}^{\prime}\left(\Delta w^{i} /(1+r)+\bar{\theta}(1-\underline{\gamma})\right)-a(1-p(\bar{\theta}) p(\underline{\gamma})) f_{\text {max }}^{\prime}>0 \\
\Rightarrow a<\frac{\tilde{u}_{C}^{\prime}\left(\Delta w^{i} /(1+r)+\bar{\theta}(1-\underline{\gamma})\right)}{(1-p(\bar{\theta}) p(\underline{\gamma})) f_{\max }^{\prime}}
\end{array}
$$

Define $\tilde{u}_{C, \min }^{\prime} \equiv \min \left\{\tilde{u}_{C}^{\prime}\left(\Delta w^{i} /(1+r)+\bar{\theta}(1-\underline{\gamma})\right)\right\}$ on $[\Delta \underline{s}, \Delta \bar{s}]$. Letting $a<\frac{\tilde{u}_{C, \min }^{\prime}}{(1-p(\bar{\theta}) p(\gamma)) f_{\max }^{\prime}}$ guarantees that condition (16) is always satisfied, and hence that $v^{\prime}>0$ everywhere. 
Finally, we note that $v$ is guaranteed to be differentiable at every point except at $\Delta w^{i}=$ $(\Delta \bar{s}-\bar{\theta}(1-\underline{\gamma}))(1+r)$, and that it is trivial to show that $f$ can be chosen to guarantee differentiability at this point as well.

We have shown that every Protestant ethics agent falls within the Calvinist subclass, and that every Calvinist agent falls within the Protestant ethics subclass, hence $\mathfrak{U}_{P E}=\mathfrak{U}_{C}$. This concludes the proof.

Corollary 1. Given any values of the aggregate variables, any Calvinist works more, saves more and has higher expected wealth than a standard agent.

Proof. Applying Lemma 1, we can define, for any Calvinist, function $\tilde{u}_{C}\left(s^{i}-S\right)=$ $E u_{C}\left(p\left(g^{i}=g \mid \gamma^{i}, s^{i}-S\right)\right)$, where $\tilde{u}_{C}^{\prime}>0$. The rest of the proof then follows closely the proof for remark 1 , and makes use of the implicit function theorem. In particular, we do not make use of the rare disasters assumption R1. Letting $\mu \in[0,1]$, we consider maximization problem $U^{i}=\left[u\left(c_{1}^{i}\right)+\beta E u\left(c_{2}^{i}\right)-d\left(l^{i}\right)\right]+\mu \tilde{u}_{C}\left(s^{i}-S\right)$, subject to the budget constraints $[B C]$. We note that $\mu=0$ corresponds to the standard agent's problem, and $\mu=1$ corresponds to the Calvinist problem.

\section{First order conditions}

$$
\begin{aligned}
F_{s} & \equiv-u^{\prime}\left(c_{1}^{i}\right)+\beta(1+r) E u^{\prime}\left(c_{2}^{i}\right)+\mu \tilde{u}_{C}^{\prime}\left(s^{i}-S\right)=0 \\
F_{l} & \equiv u^{\prime}\left(c_{1}^{i}\right) f^{\prime}\left(l^{i}\right)-d^{\prime}\left(l^{i}\right)=0 .
\end{aligned}
$$

The Hessian is then $\left[\begin{array}{cc}F_{s s} & F_{l s} \\ F_{l s} & F_{l l}\end{array}\right]$, where

$$
\begin{aligned}
F_{s s} & \equiv u^{\prime \prime}\left(c_{1}^{i}\right)+\beta(1+r)^{2} E u^{\prime \prime}\left(c_{2}^{2}\right)+\mu \tilde{u}_{C}^{\prime \prime}\left(s^{i}-S\right) \\
F_{l s} & \equiv-u^{\prime \prime}\left(c_{1}^{i}\right) f^{\prime}\left(l^{i}\right) \\
F_{l l} & \equiv u^{\prime \prime}\left(c_{1}^{i}\right)\left(f^{\prime}\left(l^{i}\right)\right)^{2}+f^{\prime \prime}\left(l^{i}\right) u^{\prime}\left(c_{1}^{i}\right)-d^{\prime \prime}\left(l^{i}\right) .
\end{aligned}
$$

Applying the implicit function theorem, we have:

$$
\left[\begin{array}{c}
\frac{d s^{*}(S, L)}{d \mu} \\
\frac{d l^{*}(S, L)}{d \mu}
\end{array}\right]=\frac{1}{\triangle}\left[\begin{array}{c}
-F_{l l} \frac{d F_{s}}{d \mu} \\
F_{l s} \frac{d F_{s}}{d \mu}
\end{array}\right]=\frac{1}{\triangle}\left[\begin{array}{c}
-F_{l l} \tilde{u}_{C}^{\prime}\left(s^{i}-S\right) \\
F_{l s} \tilde{u}_{C}^{\prime}\left(s^{i}-S\right)
\end{array}\right],
$$


where $\triangle$ is the determinant of the Hessian.

The $2 \times 2$ Hessian is negative definite and hence $\Delta>0$. It is clear that $F_{l l}<0$ and that $F_{l s}>0$, and since $\tilde{u}_{C}^{\prime}\left(s^{i}-S\right)>0$, it follows that $\frac{d s^{*}(S, L)}{d \mu}>0$ and that $\frac{d l^{*}(S, L)}{d \mu}>0$. It is then immediate that $\frac{d E w^{*}(S, L)}{d \mu}=(1+r) \frac{d s^{*}(S, L)}{d \mu}>0$. Finally, since the result holds for any aggregate variables, this concludes the proof.

Corollary 2. The equilibrium outcome of an economy consisting of Calvinists is Pareto inefficient. Calvinists overwork and oversave in equilibrium: let $l^{*}, s^{*}$ be the equilibrium choice of labor and savings, respectively, which is identical for each agent, for Calvinist utility $U_{C} \in \mathfrak{U}_{C}$. Then there is an $l<l^{*}, s<s^{*}$ such that, if each agent chooses labor $l$ and savings $s$, then $U_{C}(l, s)>U_{C}\left(l^{*}, s^{*}\right)$.

Proof. It is clear that each Calvinist agent has a unique optimal solution, and, since all agents are identical, that $l^{*}, s^{*}$ are the identical each agent. Hence $L^{*}=l^{*}, S^{*}=s^{*}$ are the aggregate variables in equilibrium. Each Calvinist agent then receives utility:

$$
u_{1}\left(c_{1}^{*}, l^{*}\right)+E u_{2}\left(c_{2}\left(s^{*}\right)\right)+E u_{C}\left(p\left(g^{i}=g \mid \gamma^{i}, 0\right)\right)
$$

where $c_{1}^{*}=f\left(l^{*}\right)-s^{*}$ is the associated period 1 consumption, and $c_{2}^{*}$ is the associated period 2 consumption (given the realized period 2 shock). Note that the relative savings term in the Calvinist function $u_{C}$ is 0 , since $s^{*}-S^{*}=s^{*}-s^{*}$.

Now consider instead the equilibrium $\tilde{l}^{*}, \tilde{s}^{*}$ for standard agents, i.e. agents which maximize $\left.u_{1}\left(c_{1}, l\right)+E u_{2}\left(c_{2}\right)\right)$ subject to the same budget constraints $[B C]$. Then $\tilde{l}^{*}, \tilde{s}^{*}$ is clearly unique; moreover $\tilde{l}^{*}<l^{*}, \tilde{s}^{*}<s^{*}$ by Corollary 1. If each Calvinist agent were instead to choose labor $\tilde{l}^{*}$ and savings $\tilde{s}^{*}$ (from which it follows that aggregate labor and savings would be $\tilde{L}^{*}=\tilde{l}^{*}$ and $\tilde{S}^{*}=\tilde{s}^{*}$, respectively) their expected utility would be:

$$
u_{1}\left(\tilde{c}_{1}^{*}, \tilde{l}^{*}\right)+E u_{2}\left(c_{2}\left(\tilde{s}^{*}\right)\right)+E u_{C}\left(p\left(g^{i}=g \mid \gamma^{i}, 0\right)\right) .
$$

Note that here as well, the relative savings term in the Calvinist function $u_{C}$ is 0 , since $\tilde{s}^{*}-\tilde{s}^{*}=0$. Comparing expressions 20 and 21, the last term is the same in both, but $u_{1}\left(\tilde{c}_{1}^{*}, \tilde{l}^{*}\right)+E u_{2}\left(c_{2}\left(\tilde{s}^{*}\right)\right)>u_{1}\left(c_{1}^{*}, l^{*}\right)+E u_{2}\left(c_{2}\left(s^{*}\right)\right)$, since $\tilde{l}^{*}, \tilde{s}^{*}$ is the unique maximizer of the expression. It follows that there would be therefore be a Pareto improvement (each Calvinist agent would have higher utility) if they each chose to work and save $\tilde{l}^{*}$ and $\tilde{s}^{*}$, respectively. This concludes the proof. 
Some models in the existing literature associate $K U J$ preferences with an agent's propensity to increase his own consumption as aggregate consumption increases; the next result provides the conditions under which this occurs for a Calvinist. This property is a function of the rate at which informativeness increases with $s^{i}-S$ relative to the preferences for early resolution of uncertainty, although we abstract from this point.

Remark 3. Given any values of the aggregate variables, the following statement holds. If, for Calvinist agent $i, \tilde{u}_{C}$ (as defined in Lemma 1) is concave, then Calvinist $i$ works more, saves more and has higher expected consumption $E c_{2}^{i}$ as expected consumption $E C_{2}$ increases.

Proof. We again apply the implicit function theorem. Using the first order conditions and the Hessian from Corollary 1, we have:

$$
\left[\begin{array}{c}
\frac{d s^{*}(S, L)}{d E C_{2}} \\
\frac{d l^{*}(S, L)}{d E C_{2}}
\end{array}\right]=\frac{1}{\triangle}\left[\begin{array}{c}
-F_{l l} \frac{d F_{s}}{d E C_{2}} \\
F_{l s} \frac{d F_{s}}{d E C_{2}}
\end{array}\right]=\frac{1}{\triangle}\left[\begin{array}{c}
F_{l l} \tilde{u}_{C}^{\prime \prime}\left(s^{i}-S\right) \\
-F_{l s} \tilde{u}_{C}^{\prime \prime}\left(s^{i}-S\right)
\end{array}\right]
$$

We have that $\triangle>0, F_{l l}<0$ and $F_{l s}>0$. Moreover, by the concavity assumption, $\tilde{u}_{C}^{\prime \prime}\left(s^{i}-S\right)<0$, and it therefore follows that $\frac{d s^{*}(S, L)}{d E C_{2}}>0$ and that $\frac{d l^{*}(S, L)}{d E C_{2}}>0$. It is then immediate that $\frac{d E c_{2}^{*}(S, L)}{d E C_{2}}>0$. The result holds for any aggregate variables, which concludes the proof.

\section{References}

[1] A. B. Abel. Asset prices under habit formation and catching up with the Joneses. American Economic Review, 80(2):38-42, 1990.

[2] B. Arruñada. Protestants and Catholics: Similar work ethic, different social ethic. Economic Journal, 120(547):890-918, 2010.

[3] N. Augenblick, J.M. Cunha, and E. D. Dal Bó. The economics of faith: An experiment on time preference two weeks before the apocalypse. Mimeo, 2012.

[4] C. Azzi and R. Ehrenberg. Household allocation of time and church attendance. Journal of Political Economy, 83(1):27-56, 1975.

[5] L. S. Bagwell and B. D. Bernheim. Veblen effects in a theory of conspicuous consumption. American Economic Review, 86(3):349-373, 1996. 
[6] R. J. Barro. Rare disasters, asset prices, and welfare costs. American Economic Review, 99(1):243-264, 2009.

[7] S. O. Becker and L. Woessmann. Was Weber wrong? a human capital theory of Protestant economic history. Quarterly Journal of Economics, 124(2):531-596, 2009.

[8] R. Benabou and J. Tirole. Willpower and personal rules. Journal of Political Economy, 112(4):848-886, 2004.

[9] R. Benabou and J. Tirole. Belief in a just world and redistributive politics. Quartely Journal of Economics, 121(2):699-746, 2006.

[10] R. Benabou and J. Tirole. Identity, dignity and taboos: Beliefs as assets. Quarterly Journal of Economics, 126(2):805-855, 2011.

[11] E. Berman. Sects, subsidy and sacrifice: an economist's view of Ultra-Orthodox Jews. Quarterly Journal of Economics, 115(3):905-953, 2000.

[12] A. Bisin and T. Verdier. The economics of cultural transmission and the dynamics of preferences. Journal of Economic Theory, 97:298-319, 2001.

[13] U. Blum and L. Dudley. Religion and economic growth: Was Weber right? Journal of Evolutionary Economics, 11:207-230, 2001.

[14] R. Bodner and D. Prelec. Self-Signaling and Diagnostic Utility in Everyday DecisionMaking. Isabelle Brocas and Juan Carrillo, eds., Collected Essays in Psychology and Economics, Oxford University Press, Oxford UK, 2003.

[15] M. Brunnermeier and J. Parker. Optimal expectations. American Economic Review, 95(4):1092-1118, 2005.

[16] J. Y. Campbell and J. H. Cochrane. By force of habit: A consumption-based explanation of aggregate stock market behavior. Journal of Political Economy, 107(2):205$251,1999$.

[17] D. Cantoni. The economic effects of the protestant reformation: Testing the Weber hypothesis in the German lands. Mimeo, 2010.

[18] A. Caplin and J. Leahy. Psychological expected utility theory and anticipatory feelings. Quartely Journal of Economics, 116(1):55-79, 2001.

[19] T. V. Cavalcanti, S. L. Parente, and R. Zhao. Religion in macroeconomics: a quantitative analysis of Weber's thesis. Economic Theory, 32:105-123, 2007. 
[20] E. Dal Bó and M. Tervio. Self-esteem, moral capital, and wrongdoing. Journal of the European Economic Association, forthcoming, 2012.

[21] B. Dupor and W. Liu. Jealousy and equilibrium overconsumption. American Economic Review, 93(1):423-428, 2003.

[22] R. B. Ekelund, R. F. Hebert, and R. D. Tollison. An economic analysis of the Protestant reformation. Journal of Political Economy, 110(3):646-671, 2002.

[23] J. Elster. Explaining Social Behavior: More Nuts and Bolts for the Social Sciences. Cambridge University Press, New York NY, 2007.

[24] L. Epstein and S. Zin. Substitution, risk aversion, and the temporal behavior of consumption and asset returns: A theoretical framework. Econometrica, 57(4):937969, 1989.

[25] J. Gali. Keeping up with the Joneses: Consumption externalities, portfolio choice and asset prices. Journal of Money, Credit and Banking, 26(1):1-8, 1994.

[26] J. J. Ganuza and J. S. Penalva. Signal orderings based on dispersion and the supply of private information in auctions. Econometrica, 78(3):1007-1030, 2010.

[27] I. Gilboa. Theory of Decision under Uncertainty. Cambridge University Press, New York NY, 2009.

[28] E. L. Glaeser and S. Glendon. Incentives, predestination and free will. Economic Inquiry, 36(3):429-443, 1998.

[29] S. Grant, A. Kajii, and B. Polak. Temporal resolution of uncertainty and recursive non-expected utility models. Econometrica, 68(2):425-434, 2000.

[30] L. Guisi, P. Sapienza, and L. Zingales. People's opium? religion and economic attitudes. Journal of Monetary Economics, 50:225-282, 2003.

[31] L. Guisi, P. Sapienza, and L. Zingales. Does culture affect economic outcomes? The Journal of Economic Perspectives, 20(2):23-48, 2006.

[32] L. R. Iannacconne. Sacrifice and stigma: Reducing free-riding in cults, communes and other collectives. Journal of Political Economy, 100(2):271-291, 1992.

[33] S. K. Kim. Efficiency of an information system in an agency model. Econometrica, 63(1):89-102, 1995. 
[34] B. Koszegi. Ego utility, overconfidence, and task choice. Journal of the European Economic Association, 4(4):673-707, 2006.

[35] D. Kreps and E. Porteus. Temporal resolution of uncertainty and dynamic choice theory. Econometrica, 46(1):185-200, 1978.

[36] G. Levy and R. Razin. Calvin's Reformation in Geneva: self and social signalling. Journal of Public Economy Theory, forthcoming, 2012.

[37] G. Levy and R. Razin. Religious beliefs, religious participation and cooperation. American Economic Journal: Microeconomics, 4(3):121-151, 2012.

[38] G. Levy and R. Razin. Rituals or good works: Social signalling in religious organizations. mimeo, 2012.

[39] L. Ljungqvist and H. Uhlig. Tax policy and aggregate demand management under catching up with the Joneses. American Economic Review, 90(3):356-366, 2000.

[40] F. Maccheroni, M. Marinacci, and A. Rustichini. Social decision theory: Choosing within and between groups. Review of Economic Studies, forthcoming, 2012.

[41] G. A. Quattrone and A. Tversky. Causal versus diagnostic contingencies: On selfdeception and on the voter's illusion. Journal of Personality and Social Psychology, 46(2):237-248, 1984.

[42] M. Rege. Why do people care about social status? Journal of Economic Behavior and Organization, 66:233-242, 2008.

[43] G. Tabellini. The scope of cooperation: Values and incentives. Quarterly Journal of Economics, 123(3):905-950, 2008.

[44] M. Weber. The Protestant Ethic and the Spirit of Capitalism. HarperCollins, New York NY, 1930.

[45] M. Weber. The Protestant Ethic and the Spirit of Capitalism. Routledge Classics, New York NY, 2002.

[46] G. Wu. Anxiety and decision making with delayed resolution of uncertainty. Theory and Decision, 46:159-198, 1999. 